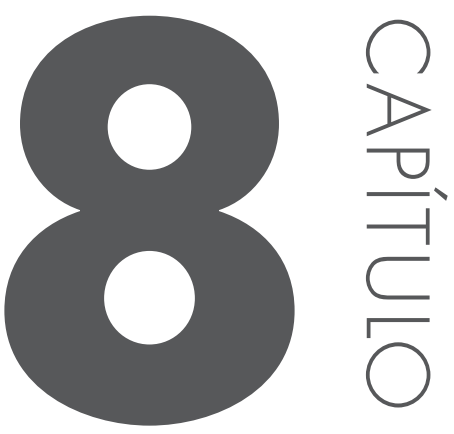

\title{
MATERIAIS LIGNOCELULÓSICOS COMO MATÉRIA-PRIMA PARA A OBTENÇÃO DE BIOMOLÉCULAS DE VALOR COMERCIAL
}

Cristine Rodrigues

Adenise Lorenci Woiciechowski

Luiz Alberto Junior Letti

Susan Grace Karp

Francieli Danubia Goelzer

Keli Cristina Alvim Sobral

Jesus Davi Coral

Tania Sila Campioni

Marcelo Adriano Corrêa Maceno

Carlos Ricardo Soccol

\subsection{INTRODUC̣ÃO}

O elevado consumo de combustíveis fósseis, especialmente dos produtos derivados do petróleo, tem gerado graves problemas ambientais. Alguns dos principais fatores das mudanças climáticas são causados pelas emissões de gases do efeito estufa (green house gases - GHG), tais como gás carbônico 
$\left(\mathrm{CO}_{2}\right)$, metano $\left(\mathrm{CH}_{4}\right)$ e óxido nitroso $\left(\mathrm{N}_{2} \mathrm{O}\right)$, produzidos na combustão de combustíveis fósseis e pelo uso inadequado da terra por atividades humanas ${ }^{1}$. Os problemas ocasionados pelo uso de combustíveis fósseis podem ser reduzidos pela substituição total ou parcial por biocombustíveis, menos poluentes, obtidos de fontes renováveis. A produção e a comercialização de biocombustíveis vêm sendo incrementadas nos últimos anos².

O etanol está presente na matriz energética de muitos países como um dos biocombustíveis mais promissores como forma de diminuir a dependência dos combustíveis fósseis, especialmente no transporte rodoviário. Pode ser produzido a partir de diferentes matérias-primas, tais como: cana-de-açúcar, milho, arroz, batata, entre outras fontes de produtos de alimentos. Isso gera uma competição entre a produção de alimentos e a produção de combustíveis.

No sentido de evitar esse problema, uma fonte importante e promissora para a produção de etanol é o material lignocelulósico, principalmente os resíduos agroindustriais, tais como resíduos do processamento da palma (dendê), bagaço de cana, resíduos municipais, palha de milho, trigo, arroz, pele de mandarina, limão, laranja, entre outros, sendo essas as fontes mais usadas e pesquisadas na atualidade ${ }^{2,3}$.

O material lignocelulósico é composto principalmente por celulose, hemicelulose e lignina, numa estrutura cristalina vegetal altamente estável que deve ser rompida mediante pré-tratamentos para disponibilizar a fração sacarídica (celulose e hemicelulose) na forma de açúcares fermentescíveis ${ }^{2,4}$.

Antes de qualquer tratamento termoquímico, a secagem é uma das primeiras etapas do processamento dos resíduos lignocelulósicos, principalmente para aqueles que necessitam ser transportados ou estocados. Essa etapa é necessária para reduzir a atividade de água, com consequente diminuição da velocidade de reações de deterioração do material, do crescimento microbiano, de processos químicos de escurecimento por oxidação e atividade enzimática ${ }^{5}$.

$\mathrm{Na}$ sequência, etapas de moagem são necessárias para aumentar a área superficial, através da redução dos tamanhos de partícula, além de diminuir o grau de polimerização do resíduo ${ }^{6}$ e uniformizar o tamanho das partículas para melhorar a eficiência dos tratamentos subsequentes. O tamanho das partículas de uma amostra é um dos principais fatores quando se estuda o pré-tratamento de resíduos, pois tem influência na área de contato e difusão dos reagentes químicos na estrutura lignocelulósica, que são fenômenos de superfície ${ }^{7,8}$. 
Novos processos, como a extrusão, congelamento e o uso de irradiação por micro-ondas, têm sido utilizados para preparar o resíduo lignocelulósico para as etapas posteriores de pré-tratamentos químicos e enzimáticos ${ }^{9,10}$. Entretanto, esses processos de pré-tratamentos físicos demandam grande quantidade de energia, aumentando o custo do processo, sem remoção da lignina ${ }^{11}$.

No sentido de contribuir para os estudos no aproveitamento desses materiais, neste capítulo serão descritos os principais processos de pré-tratamentos utilizados para a obtenção de diferentes biomoléculas a partir de materiais lignocelulósicos.

\subsection{HISTÓRICO}

Os materiais lignocelulósicos têm sido utilizados pelo homem desde a Antiguidade para a obtenção de energia. A queima da madeira na forma de galhos e folhas foi a principal fonte de energia térmica e luminosa usada por milênios, auxiliando no preparo de alimentos, na defesa do homem contra predadores e no aquecimento durante os períodos de frio intenso.

Durante a Revolução Industrial, nos século XVIII, a principal fonte de energia passou a ser o carvão de origem mineral, que desempenhou papel fundamental para o estabelecimento e consolidação das primeiras matrizes industriais na Inglaterra e, em um segundo momento, na Europa, nas Américas e ao redor de todo o mundo. A partir do século XX, com os automóveis, o petróleo assumiu o papel central como matéria-prima para obtenção de combustíveis e energia. No entanto, problemas ambientais (e também econômicos e políticos) decorrentes do uso do carvão mineral e do petróleo chamam novamente a atenção do mundo para o uso de matérias-primas celulósicas, as biomassas, como provedoras de energia e de outras biomoléculas de valor econômico. As fontes de energia classificadas como renováveis, limpas e verdes, como as biomassas, tendem a assumir papel central na economia e política em quase todos os países desenvolvidos e em desenvolvimento.

Notadamente o etanol obtido a partir de açúcares diretamente fermentescíveis e mais recentemente a partir de materiais lignocelulósicos sacarificados (etanol de segunda geração) tem um papel importante nesse histórico.

As primeiras notas sobre uso de material lignocelulósico para obtenção de etanol datam de 1819, por Braconnet. Em 1894, Simonsen tratou serragem com ácidos diluídos e altas pressões, processo que gerou etanol a taxas de $7 \mathrm{~L}$ a $9 \mathrm{~L}$ para cada $100 \mathrm{~kg}$ de material seco. A partir do final do século 
XIX o ácido sulfúrico passou a ser empregado nas hidrólises. Estados Unidos (resíduos de pinus) e França (serragem) se destacavam na produção de etanol celulósico em escala industrial, mas ainda com rendimentos bastante modestos. Durante a Primeira Guerra Mundial o interesse pela produção de etanol a partir de madeira se intensificou, notadamente pela Alemanha, pela necessidade de suplementar o abastecimento energético ${ }^{12}$.

As primeiras tentativas de se utilizar enzimas para hidrólise de materiais lignocelulósicos se deram no início da década de 1970, no Japão. Em decorrência dessa tecnologia, logo surgiram processos de sacarificação e fermentação simultânea. O Brasil, no final da década de 1970 (com o projeto COALBRA) tentou implantar uma usina experimental para produção de etanol celulósico, em Uberlândia, Minas Gerais. A unidade teria capacidade de produção diária de $30.000 \mathrm{~L}$ de etanol e utilizaria o eucalipto da região como matéria-prima. O projeto não obteve êxito devido a uma série de questões técnicas, como, por exemplo, a dificuldade de se trabalhar com o tipo de madeira disponível e problemas com o processo fermentativo. $\mathrm{Na}$ mesma década, outra tentativa (também sem êxito) se deu na cidade de Lorena, no estado de São Paulo, com uma unidade piloto de hidrólise ácida (processo Madison), que faz a hidrólise contínua da madeira em um sistema de percolação de ácido sulfúrico diluído. Na década de 1980 a empresa Dedine (São Paulo) estabeleceu um processo de hidrólise do bagaço de cana (com ácidos concentrados) seguido por fermentação para obtenção de etanol. No entanto, as pentoses geradas durante a hidrólise eram subaproveitadas. Atualmente diversas empresas (principalmente norte-americanas) investem em produção de etanol de segunda geração. No Brasil, destaca-se uma unidade piloto na cidade de Piracicaba, São Paulo, em funcionamento, com capacidade diária de produção de $1.000 \mathrm{~L}$ de etanol. Tal unidade é fruto de uma parceria entre a Novozymes (multinacional dinamarquesa) e o Centro de Tecnologia Canavieira (CTC) ${ }^{13}$.

Além do etanol de segunda geração obtido a partir de celulose e/ou hemicelulose, o potencial dos materiais lignocelulósicos como fonte de outras biomoléculas tem sido explorado recentemente. Muitas pesquisas têm sido feitas, e novas tecnologias vêm sendo desenvolvidas com esse propósito (e também para aumentar os rendimentos de produção de etanol de segunda geração). Por isso, atualmente são valorizados pré-tratamentos de materiais lignocelulósicos que preservem seus polissacarídeos e açúcares totais ${ }^{14}$, bem como a lignina.

Tem-se evidenciado, por exemplo, o potencial uso de componentes hemicelulósicos como biopolímeros ${ }^{15}$ em indústrias de alimentos, biomédicas e 
de cosméticos ${ }^{16}$; como polímeros iônicos, hidrogéis para liberação gradativa de drogas ${ }^{17}$ e uma infinidade de possibilidades de usos para frações específicas, por exemplo, glucomananas e arabinogalactanas como ingredientes de alimentos, bebidas e na medicina ${ }^{18}$.

Recentemente, muita atenção tem se voltado também à lignina. Em geral ela é queimada para a produção direta de energia térmica, mas esse processo é pouco vantajoso por exigir uma etapa prévia de concentração para diminuir a quantidade de água. Alternativas mais interessantes do ponto de vista econômico e ambiental são, dentre outras, a própria produção de biocombustíveis e geração de biomoléculas como aldeídos aromáticos e produtos fenólicos. Conversão hidrotérmica, pirólise, degradação enzimática, degradação fotocatalizada e oxidação por irradiação de micro-ondas e biotransformação são algumas das técnicas atualmente estudadas para agregar valor às ligninas ${ }^{19}$.

\subsection{RESÍDUOS LIGNOCELULÓSICOS}

Os materiais lignocelulósicos são os materiais orgânicos mais abundantes da biosfera, representando aproximadamente $60 \%$ da biomassa vegetal. Podem ser divididos em seis grupos principais: resíduos de colheitas (bagaço de cana, palha de milho etc.), madeira de lei (álamo alpino e álamo), madeira de conífera (pinheiro e abeto), resíduos celulósicos (lodo de papel e papel reciclado, jornais etc.), biomassas herbáceas (feno de alfafa, caniço-malhado etc.) e resíduos sólidos municipais ${ }^{20}$.

Esses materiais apresentam uma rede complexa e resistente composta principalmente por lignina $(10 \%$ a $30 \%)$, hemicelulose $(15 \%$ a $35 \%)$ e celulose $(30 \%$ a $50 \%)$, sendo a concentração de cada um desses elementos variável de acordo com o tipo de matéria-prima em questão, idade e estágio vegetativo $^{21,22}$.

O principal componente dos materiais lignocelulósicos é a celulose, polissacarídeo formado por moléculas de glicose unidas através de ligações $\beta$-1,4-glicosídicas. Cadeias de celulose são estabilizadas e ligadas entre si por pontes de hidrogênio intra e intermoleculares, formando as fibrilas elementares, que contêm cerca de 36 cadeias justapostas e apresentam $3 \mathrm{~nm}$ a $4 \mathrm{~nm}$ de largura. Essas fibrilas são unidas umas às outras através da hemicelulose, o segundo mais abundante componente da lignocelulose, que é um polissacarídeo amorfo, composto por vários açúcares de cinco e seis carbonos, como arabinose, galactose, glicose, manose e xilose, além de desoxiaçúcares 
e ácidos urônicos. Essas estruturas são cobertas pela lignina, um polímero aromático formado por três estruturas básicas fenólicas, o álcool p-cumarílico, álcool coniferílico e o álcool sinapílico e seus derivados ${ }^{22}$.

Cada uma das porções dos materiais lignocelulósicos pode ser utilizada com uma finalidade, por exemplo, as porções celulósicas e hemicelulósicas da biomassa podem ser hidrolisadas a vários açúcares e então fermentadas. As ligninas, por sua vez, podem ser degradadas a frações de massas molares menores, sendo utilizadas em vários processos químicos, como na fabricação de espumas de poliuretanos, resinas fenólicas e epóxi, na produção de fenol e etileno, e podem ser convertidas em fibras de carbono ${ }^{23,24}$.

Os resíduos e materiais lignocelulósicos podem ser usados como matéria-prima para a produção de alimentos, combustíveis, insumos químicos, enzimas e bens de consumo diversos ${ }^{25}$. Propriedades como o teor de lignina, acessibilidade da celulose a enzimas e micro-organismos e o grau de cristalinidade da celulose determinam a digestibilidade total da biomassa e sua futura aplicabilidade.

Alguns dos subprodutos da agropecuária, como bagaço de cana, palha de cana, arroz e trigo estão sendo utilizados biotecnologicamente na produção de produtos como acetato de celulose, blendas e compósitos, etanol de segunda geração, hidroximetilfurfural, papel e celulose, revestimentos acústicos, madeira prensada, alcaloides, enzimas, xilitol, polpa celulósica, celulose bacteriana, e também na produção de energia ${ }^{26-47}$.

Embora os resíduos lignocelulósicos agroindustriais necessitem, na sua maioria, de um tratamento prévio por meio de hidrólise ácida ou enzimática para disponibilizar os açúcares fermentescíveis, é importante destacar a importância dessas matérias-primas, uma vez que apresentam baixo custo e alta disponibilidade.

A oferta de resíduos lignocelulósicos em todo o mundo corresponde a aproximadamente $2,9 \times 10^{3}$ milhões de toneladas produzidas de culturas de cereais, $3 \times 10^{3}$ da produção de sementes e 5,4 $410^{2}$ de outros tipos de cultura $^{48}$, além de 40 milhões de toneladas de materiais vegetais não comestíveis, incluindo os caules de trigo, palha de milho (os talos e folhas) e aparas de madeira da exploração madeireira, que são, em sua maioria, descartados como resíduo ${ }^{49}$.

O Brasil destaca-se mundialmente pela agricultura e pelo agronegócio, com uma grande área cultivável de grãos, cereais, frutas e principalmente com a cultura da cana-de-açúcar. $O$ último levantamento da safra 2012/2013 pela Companhia Nacional de Abastecimento (CONAB) mostrou que foram produzidas no Brasil 893,5 mil toneladas de algodão-caroço; 
96,6 mil toneladas de amendoim; 2,39 milhões de toneladas de arroz, 168,7 mil toneladas de aveia; 43,8 mil toneladas de canola; 2,3 mil toneladas de centeio; 102,8 mil toneladas de cevada; 3,11 milhões de toneladas de feijão; 68,7 mil toneladas de girassol; 15,82 milhões de toneladas de milho; 27,73 milhões de toneladas de soja; 1,89 milhões de toneladas de trigo; e 652,02 milhões de toneladas de cana-de-açúcar ${ }^{50,51}$, gerando, portanto, uma grande quantidade de subprodutos como os resíduos lignocelulósicos.

\subsection{TRATAMENTOS QUíMICOS}

\subsubsection{Pré-tratamento com ácidos}

A hidrólise ácida é um dos pré-tratamentos mais promissores e extensivamente estudados e empregados. A eficiência da obtenção de xilose a partir da hidrólise da hemicelulose pode oscilar entre $75 \%$ a $90 \%$, sendo este o principal monossacarídeo obtido; outros açúcares, como glicose e arabinose, são obtidos em menores quantidades ${ }^{52}$.

Apesar da elevada eficiência na recuperação de açúcares, a formação de subprodutos como ácido acético e furfural podem gerar problemas no processo por serem agentes inibitórios dos processos fermentativos ${ }^{53,54}$. Industrialmente se utiliza ácido diluído e condições brandas de temperatura, até $120{ }^{\circ} \mathrm{C}$, pois nessas condições é produzida menor quantidade destes inibidores da fermentação. São utilizados ácido sulfúrico $\left(\mathrm{H}_{2} \mathrm{SO}_{4}\right)$, ácido clorídrico $(\mathrm{HCl})$, ácido nítrico $\left(\mathrm{HNO}_{3}\right)$, ácido fosfórico $\left(\mathrm{H}_{3} \mathrm{PO}_{4}\right)$, sendo o $\mathrm{H}_{2} \mathrm{SO}_{4}$ o principal ${ }^{55-58}$.

No processo com ácido diluído, a produção de xilose a partir da hemicelulose é mais adequada em condições brandas de tratamento. Isto se dá pelo fato de a estrutura cristalina da celulose só ser afetada significativamente em condições mais severas. O pré-tratamento térmico pode ser realizado tanto por tempo baixo (cinco minutos) e temperatura elevada $\left(180^{\circ} \mathrm{C}\right)$ ou durante um tempo de tratamento maior ( 30 a 90 minutos) e temperaturas mais baixas $\left(120^{\circ} \mathrm{C}\right)$. Com temperaturas médias $\left(140^{\circ} \mathrm{C}\right.$ a $\left.170{ }^{\circ} \mathrm{C}\right)$ e baixas concentrações de ácido $(0,1 \%$ a $1 \%)$, pode-se alcançar taxas significativas na hidrólise da celulose, sendo que quase $100 \%$ da hemicelulose é hidrolisada ${ }^{59}$.

Estudos feitos com bagaço de palma, mediante uma hidrolise ácida, seguida de uma lavagem alcalina, mostraram que na primeira etapa houve uma remoção de $90 \%$ da hemicelulose e $32 \%$ da lignina, e após o processo 
alcalino observou-se uma deslignificação de $70 \%$, gerando uma biomassa com $82 \%$ de celulose, aumentando dessa forma a digestibilidade enzimática ${ }^{54}$.

\subsubsection{Pré-tratamento alcalino}

O principal efeito do pré-tratamento alcalino sobre a biomassa é a deslignificação (amolecimento e solubilização da lignina), tornando a hemicelulose e a celulose mais acessíveis a processos de hidrólise posteriores. $\mathrm{O}$ uso de agentes alcalinos promove um inchaço nas fibras, repercutindo nas ligações da hemicelulose e celulose, aumentando assim a porosidade da biomassa $^{60,61}$.

Os agentes alcalinos mais utilizados são: hidróxido de sódio $(\mathrm{NaOH})$, hidróxido de potássio $(\mathrm{KOH})$, hidróxido de cálcio $\left(\mathrm{Ca}(\mathrm{OH})_{2}\right)$ e amônia. Destes, o mais estudado é o $\mathrm{NaOH}^{62-65}$; entretanto, o $\mathrm{Ca}(\mathrm{OH})_{2}$ tem se mostrado efetivo como agente de pré-tratamento e é mais barato que o $\mathrm{NaOH}^{66}$. A amônia também tem sido testada para vários resíduos, sendo altamente seletiva na remoção da lignina e abertura do resíduo lignocelulósico, com a vantagem de ser facilmente recuperada devido à sua alta volatilidade ${ }^{67}$.

Nos estudos de pré-tratamento para palha de milho, Li e Kim ${ }^{68}$ obtiveram $55 \%$ de deslignificação do resíduo quando tratado com amônia aquosa a $50 \%(\mathrm{~m} / \mathrm{m})$ por quatro semanas a $30^{\circ} \mathrm{C}$, na proporção $1: 5$ (massa de resíduo/volume do álcali). O pré-tratamento também se mostrou eficiente para a acessibilidade da celulose, apresentando $86,5 \%$ de conversão em glicose. Jung et al. ${ }^{69}$ obtiveram resultados semelhantes, 43,6\% de deslignificação após o tratamento de cachos vazios de palma com amônia aquosa $14 \%$ $(\mathrm{m} / \mathrm{m})$ por 12 horas a $80{ }^{\circ} \mathrm{C}$, na proporção de $1: 12(\mathrm{~m} / \mathrm{v})$, com uma conversão de $89,6 \%$ de celulose em glicose.

A principal desvantagem de se utilizar pré-tratamento alcalino está na desacetilação da hemicelulose, gerando ácido acético em solução. Entretanto, dependendo das condições de tratamento (tempo, concentração, temperatura) e do álcali utilizado, obtêm-se bons rendimentos. Geralmente, $\mathrm{NaOH}$ e KOH são preferidos ${ }^{70}$. Outras desvantagens estão nos tempos de tratamento, que podem variar de horas até dias, e na necessidade de neutralização do hidrolisado ${ }^{6,9}$.

Brienzo, Siqueira e Milagres ${ }^{71}$ elaboraram um processo para deslignificação do bagaço de cana, maximizando a extração de hemicelulose com solução alcalina de $\mathrm{NaOH}$, peróxido de hidrogênio $\left(\mathrm{H}_{2} \mathrm{O}_{2}\right)$ e sulfato de magnésio $\left(\mathrm{MgSO}_{4}\right)$. Inicialmente, as amostras foram lavadas com solução de 
EDTA $0,2 \%(\mathrm{~m} / \mathrm{v})$, para remover traços de metais como ferro e magnésio, que interferem na oxidação pelo $\mathrm{H}_{2} \mathrm{O}_{2}$. Nas condições utilizadas $(6 \%$ de $\mathrm{H}_{2} \mathrm{O}_{2}$, pH 11,6, 4 horas e $20{ }^{\circ} \mathrm{C}$ ), obteve-se $86 \%$ de conversão de hemicelulose e máxima deslignificação (94,1\%). Melhor resultado, 94,5\% de conversão de hemicelulose, foi obtido nas condições de $4 \%$ de $\mathrm{H}_{2} \mathrm{O}_{2}, 0,25 \%$ de $\mathrm{MgSO}_{4}$, pH 11,6; 10 horas e $40{ }^{\circ} \mathrm{C}$, mas houve uma redução na deslignificação $(91 \%)$. Esse estudo indica que o processo alcalino é eficiente tanto na deslignificação como na conversão de hemicelulose, dependendo das condições utilizadas.

\subsubsection{Pré-tratamentos físico-químicos}

Nos pré-tratamentos físico-químicos são utilizados agentes químicos ácidos, alcalinos ou água, conjuntamente com processos físicos tais como: incremento de temperatura ou pressão, processos de descompressão rápida, uso de ultrassom, entre outros, para atingir dois propósitos: aumentar a área superficial do material sólido e hidrolisar parcial ou totalmente a biomassa. Os principais processos são descritos a seguir.

\subsubsection{Explosão a vapor (SE)}

A explosão a vapor (do inglês steam explosion - SE) é uma técnica de pré-tratamento que envolve o tratamento da biomassa com vapor a elevadas temperaturas $\left(190{ }^{\circ} \mathrm{C}\right.$ a $240{ }^{\circ} \mathrm{C}$ ) e pressões (20 bar a 50 bar) com tempos de residência de 3 a 20 minutos, seguido por descompressão rápida, que rompe a estrutura do material fibroso que é recolhido em um ciclone em porções sólidas e um resíduo líquido ${ }^{72-74}$.

O sólido tem a estrutura química modificada, apresentando uma maior área superficial. O resíduo líquido é de cor marrom escura, contendo o produto da hidrólise (despolimerização) da hemicelulose (xilose e arabinose), parte da celulose hidrolisada a glicose, e parte da lignina solúvel em meio ácido. Devido a elevadas temperaturas de tratamento térmico, produzem-se compostos inibitórios para os processos fermentativos: ácido acético, furfural e hidroximetil furfural (HMF). Tais compostos têm sido reportados por diversos autores como os principais subprodutos formados pela SE e presentes no licor gerado ${ }^{58,75-79}$. 
O processo de SE pode ter caráter autocatalítico, isto é: o processo gera hidrólise parcial da biomassa sem presença de catalisador algum. No entanto, a biomassa pode ser impregnada com agentes ácidos para melhorar o pré-tratamento. São ácidos minerais como os ácidos sulfúrico, fosfórico e sulfuroso e agentes alcalinos como amônia e hidróxido de sódio ${ }^{80,81}$.

$\mathrm{Na}$ Tabela 8.1 são apresentados alguns dados sobre SE para diferentes tipos de biomassa.

Tabela 8.1 Tipos de biomassa e condições de operação da SE

\begin{tabular}{|c|c|c|c|c|c|c|}
\hline BIOMASSA & $\begin{array}{c}\text { TEMPERATURA } \\
\left({ }^{\circ} \mathrm{C}\right)\end{array}$ & $\begin{array}{l}\text { PRESSÃO } \\
\text { (MPA) }\end{array}$ & $\begin{array}{l}\text { TEMPO } \\
\text { (MIN.) }\end{array}$ & CATALISADOR & $\begin{array}{c}\text { AÇUCARES } \\
\text { RECUPERADOS }\end{array}$ & REFERÊNCIA \\
\hline Bagaço de cana & 200 & n. r. & 5 & $\mathrm{SO}_{2} 2 \%$ & $\begin{array}{l}\text { Glicose: 2,6a } \\
\text { Xilose: 10,9 a } \\
\text { Arabinose: 1,5 a }\end{array}$ & 82 \\
\hline Palha de trigo & 190 & n. r. & 10 & $\mathrm{H}_{2} \mathrm{SO}_{4} 0,2 \%$ & $\begin{array}{c}\text { Glicose: 2,3 a } \\
\text { Xilose: } 21,8^{a} \\
\text { Arabinose: } 3,3^{\circ}\end{array}$ & 82 \\
\hline Palha de milho & 200 & 1,6 & 5 & sem & $\begin{array}{c}\text { Glicose: } 2,9 \text { b } \\
\text { Xilose: } 5,1^{\text {b }} \\
\text { Arabinose: 1,37 b }\end{array}$ & 83 \\
\hline $\begin{array}{l}\text { Cachos vazios } \\
\text { de palma }\end{array}$ & 140 & 0,28 & 15 a 60 & sem & $\begin{array}{c}\text { Celulose: } 304^{c} \\
\text { Hemicelulose: } 299 \text { c }\end{array}$ & 84 \\
\hline
\end{tabular}

Legenda: n. r., não reportado; ${ }^{0} \mathrm{~g} \mathrm{~L}{ }^{-1}, \mathrm{~b} \mathrm{~g} / 100 \mathrm{~g}$ de biomassa; ${ }^{~} \mathrm{~g} . \mathrm{Kg}^{-1}$ de biomassa.

\subsubsection{2 Água quente (LHW)}

O pré-tratamento de material lignocelulósico com água quente (do inglês hot liquid water - LHW) é uma técnica similar à explosão a vapor, usando água quente ou vapor saturado para hidrolisar a hemicelulose. Devido ao uso de temperaturas mais baixas que a SE, a celulose permanece mais ligada à estrutura da biomassa e a formação de inibidores é menor ${ }^{85-87}$.

A seleção dos valores das variáveis do processo como temperatura, tempo de residência, quantidade de catalisador e tipo de catalisador dependem do tipo de biomassa. A temperatura típica oscila entre $170{ }^{\circ} \mathrm{C}$ e $230{ }^{\circ} \mathrm{C}$, as pressões ficam acima dos $5 \mathrm{MPa}$ e o tempo de residência é de cerca de cinco minutos ${ }^{6}$. O uso de temperaturas elevadas (acima de $130{ }^{\circ} \mathrm{C}$ ) dá um caráter 
de autocatálise ao processo de LHW, visto que o uso de catalisadores ácidos ou alcalinos não é necessário ${ }^{88}$.

A técnica de LHW é muito usada na indústria do papel, bem como a técnica de SE. Portanto, para se avaliar o efeito de variáveis como temperatura, tempo de residência e concentração de ácido, as mesmas correlações que são usadas em explosão a vapor são válidas para o processo de $\mathrm{LHW}^{89}$.

Na Tabela 8.2 são apresentados alguns dados reportados na literatura do uso do LHW como técnica de pré-tratamento para alguns tipos de biomassa.

Tabela 8.2 Tipos de biomassa e condições do processo de LHW sem adição de catalisadores

\begin{tabular}{cccccc}
\hline BIOMASSA & $\begin{array}{c}\text { TEMPERATURA } \\
\left({ }^{\circ} \mathrm{C}\right)\end{array}$ & $\begin{array}{c}\text { PRESSÃO } \\
\text { (MPA) }\end{array}$ & $\begin{array}{c}\text { TEMPO } \\
\text { (MIN.) }\end{array}$ & $\begin{array}{c}\text { AÇÚCARES } \\
\text { RECUPERADOS }\end{array}$ & REFERÊNCIA \\
\hline Bagaço de cana & 160 a 180 & n. r. & 20 a 40 & $\begin{array}{c}\text { Galactose: } 0,24^{\circ} \\
\text { Xilose: } 6,87^{\circ} \\
\text { Arabinose: } 0,52^{\circ}\end{array}$ & 90 \\
\hline Palha de trigo & 170 a 220 & n. r. & 0 a 40 & $\begin{array}{c}\text { Celulose: } 2,3^{b} \\
\text { Hemicelulose: } 38,5^{b}\end{array}$ & 91 \\
\hline Eucalipto (E. grandis) & 180 a 200 & n. r. & $10 a 6$ & $\begin{array}{c}\text { Glucan: } 41,9 c \\
\text { Xylan: } 1,7^{c}\end{array}$ & 92 \\
\hline
\end{tabular}

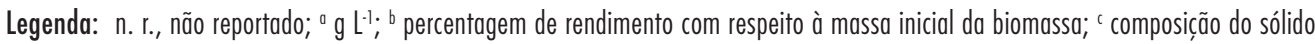
pré-tratado.

\subsubsection{Outros pré-tratamentos}

Diversos outros processos de pré-tratamento têm surgido, entre os quais se destacam o processo de explosão de fibra com amônio, (do inglês ammonia fiber expansion - AFEX), os processos de ultrassom, os líquidos iônicos, a ozonólise, dentre outros.

\subsubsection{Processo AFEX}

Neste processo, amônio líquido é adicionado ao material lignocelulósico, que é, então, tratado como na SE, isto é, a temperaturas e pressões elevadas seguidas de uma rápida descompressão $0^{93,94}$. 
As condições de operação de temperatura e tempo de tratamento utilizadas são menores quando comparadas ao processo SE. Geralmente as temperaturas estão dentro da faixa de $60{ }^{\circ} \mathrm{C}$ a $100{ }^{\circ} \mathrm{C}$ e os tempos de residência são de cinco a dez minutos.

A quantidade de amônio é de aproximadamente $1 \mathrm{~kg}$ por quilo de biomassa seca, sendo esta uma das principais desvantagens do processo, já que é necessário um sistema de recuperação eficiente do amônio, devido a fatores ambientais e econômicos ${ }^{95}$.

O processo AFEX não hidrolisa a biomassa propriamente dita, mas sim modifica a estrutura, permitindo maior área superficial para os processos posteriores de hidrólises ácida e enzimática. Essa característica se traduz em baixos rendimentos nas etapas de processamento posteriores ao AFEX, com materiais lignocelulósicos com elevados teores de lignina ${ }^{93,96}$.

\subsubsection{Ultrassom}

A técnica está pautada na formação de bolhas de cavitação dentro do meio líquido pelas ondas de ultrassom. As bolhas geradas podem implodir gerando condições extremas de temperatura e pressão $(500 \mathrm{~K}$ e $50 \mathrm{MPa})$ e cavitação, o que ocasiona uma degradação da estrutura do material lignocelulósico e produção de radicais livres ${ }^{97}$. Tem sido reportado que ultrassom com frequências de $23 \mathrm{kHz}$ a $45 \mathrm{kHz}$ incrementa a porosidade das fibras da celulose, rompe ligações $\alpha-O-4$ ou $\beta-O-4$ da lignina e diminui a cristalinidade do material lignocelulósico ${ }^{98,99}$.

A técnica de ultrassom como pré-tratamento da biomassa para produção de etanol ainda não é amplamente usada. Na Tabela 8.3 estão apresentados alguns dados e referências do uso desta técnica.

Tabela 8.3 Biomassa pré-tratada com ultrassom

\begin{tabular}{|c|c|c|c|c|c|}
\hline BIOMASSA & MEIO & $\begin{array}{c}\text { TEMPERATURA } \\
\left({ }^{\circ} \mathrm{C}\right)\end{array}$ & $\begin{array}{l}\text { TEMPO } \\
\text { (MIN.) }\end{array}$ & $\begin{array}{c}\text { AḈCARES } \\
\text { RECUPERADOS }\end{array}$ & REFERÊNCIA \\
\hline Bagaço de cana & $\begin{array}{c}\mathrm{NaOH}(0,25 \\
-3,35 \%)\end{array}$ & 120 & 60 & $\begin{array}{c}\text { Glucose: } 0,71^{0} \\
\text { Xilose } 9,0^{\circ} \\
\text { Arabinose } 1,42^{\circ}\end{array}$ & 100 \\
\hline Kenaf & Água & 30 & 0 a 120 & $\begin{array}{c}\text { Cellulose:38b } \\
\text { Hemicellulose:58 }\end{array}$ & 98 \\
\hline
\end{tabular}




\begin{tabular}{cccccc}
\hline BIOMASSA & MEIO & $\begin{array}{c}\text { TEMPERATURA } \\
\left({ }^{\circ} \mathrm{C}\right)\end{array}$ & $\begin{array}{c}\text { TEMPO } \\
\text { (MIN.) }\end{array}$ & $\begin{array}{c}\text { AC̦ÚCARES } \\
\text { RECUPERADOS }\end{array}$ & REFERÊNCIA \\
\hline $\begin{array}{c}\text { Cachos vazios } \\
\text { de palma }\end{array}$ & $\mathrm{H}_{2} \mathrm{SO}_{4}(2 \% \mathrm{v} / \mathrm{v})$ & 25 & $15 \mathrm{a} 45$ & Xylose $60^{\circ}$ & 99 \\
\hline
\end{tabular}

Legenda: ${ }^{a} \mathrm{~g} \mathrm{~L}{ }^{-1} ;{ }^{b}$ percentagem de recuperação; ‘ ${ }^{c}$ rendimento de xilose depois do pré-tratamento.

\subsubsection{Pré-tratamento biológico - Biopolpação}

A biopolpação é um método empregado para a obtenção da polpa de celulose a partir de material lignocelulósico por meio da utilização de micro-organismos que degradam seletivamente a lignina e a hemicelulose e preferencialmente mantêm intacta a celulose.

Durante o processo de biopolpação o grau de polimerização da celulose pode ser reduzida aumentando a proporção de regiões terminais, que é mais suscetível à hidrólise. Grande quantidade de hemicelulose é hidrolisada, enquanto a lignina também é em grande parte retirada ou degradada ${ }^{101}$.

A biopolpação é um processo complexo que envolve várias enzimas mediadas por uma série de pequenas moléculas que trabalham sinergicamente. Micro-organismos (fungos e bactérias), ou somente enzimas produzidas por eles, são utilizadas no tratamento biológico. No mercado podem ser encontradas essas preparações enzimáticas, contendo enzimas hidrolíticas e oxidativas, que são amplamente usadas no lugar dos micro-organismos ${ }^{102}$.

Em geral, a tecnologia de bioprocessamento da matéria-prima lignocelulósica e/ou dos seus constituintes para bioprodutos é composta por três etapas: projeto inicial do processo, otimização do sistema e desenvolvimento do modelo. O processamento envolve o uso de biocatalisadores, micro-organismos ou as suas próprias enzimas ou enzimas de outros organismos para promover a bioconversão de matérias-primas em novos produtos, a recuperação e purificação de tais bioprodutos e, posteriormente, ajustes do downstream ${ }^{103}$.

Normalmente o bioprocesso é realizado por fungos basidiomicetos de degradação da madeira, e após a degradação fúngica o resultado são carboidratos facilmente metabolizáveis ${ }^{104}$. Fungos de degradação "branca", os principais basidiomicetos utilizados no tratamento biológico de resíduos agroindustriais, são seletivos para a quebra da lignina e da hemicelulose ${ }^{105}$. A degradação fúngica da biomassa lignocelulósica é amplamente utilizada 
e ocorre no meio extracelular, pela ação de enzimas secretadas no meio pelos micro-organismos. Os fungos possuem um sistema enzimático extracelular de alta eficiência responsável pela degradação, dentre eles o sistema de hidrólise, que produz hidrolases responsáveis pela degradação dos polissacarídeos, além de um sistema ligninolítico oxidativo que degrada a lignina e abre os anéis fenólicos ${ }^{106}$.

Pleurotus sajor-caju, P. pulmonarius e Lentinus edodes foram utilizados para o tratamento biológico de grãos de cevada, e conseguiram remover a lignina e a hemicelulose, deixando a celulose relativamente intacta para servir de alimento para ruminantes. Concluiu-se, ainda, que a fermentação no estado sólido com esses fungos superiores leva algum tempo para acontecer, e que as enzimas lignocelulolíticas são produzidas durante o metabolismo secundário na fase estacionária, quando ocorre a quebra da lignina. Durante a fase de crescimento, hemicelulose e outros compostos hidrossolúveis são preferencialmente utilizados ${ }^{107}$.

No Japão, o pré-tratamento biológico da palha de arroz com fungos da degradação branca (Phanerochaete chrysosporium, Trametes versicolor, Ceriporiopsis subvermispora e Pleurotus ostreatus), em regime de fermentação no estado sólido, foi usado para aumentar a suscetibilidade dos carboidratos à hidrólise enzimática. P. ostreatus se destacou na degradação seletiva da lignina após 60 dias de cultivo, enquanto a celulose e hemicelulose ficaram praticamente intactas. Quando o teor de lignina foi reduzido para menos de $15 \%(\mathrm{~m} / \mathrm{m})$, houve um incremento significativo na degradação enzimática dos carboidratos ${ }^{108}$.

Dias et al. ${ }^{109}$ indicam aumento considerável da acessibilidade de celulose na palha de trigo (três a quatro vezes), após pré-tratamento com basidiomicetos Irpex lacteus e EUC-1 em fermentação no estado sólido. Ambas as cepas revelaram baixas atividades celulolíticas e xilanolíticas, mas altas atividades ligninolíticas, especialmente da enzima manganês peroxidase $(\mathrm{MnP})$. A alta atividade de $\mathrm{MnP}$ parece ser um pré-requisito importante para o sucesso da biopolpação fúngica, uma vez que, no caso de I. lacteus, a atividade de lacase não foi detectada durante todos os períodos de pré-tratamentos. A razão inicial de celulose/lignina na palha de trigo de 2,7 foi aumentada para 5,9 e 4,6 (percentagem de celulose/percentagem de lignina) após o pré-tratamento por basidiomicetos EUC-1 e I. lacteus, respectivamente. Portanto, essas cepas poderiam ser utilizadas para promover a bioconversão de materiais lignocelulósicos.

Segundo Arora e colaboradores ${ }^{110}$, o actinomiceto aeróbio Streptomyces griseus B1, isolado do solo, é capaz de produzir altos níveis de enzimas 
hidrolíticas de lignocelulose. O micro-organismo atacou e modificou a lignina até certo ponto, transformou-a em fragmentos solúveis, mas não a utilizou como fonte de carbono.

Três bactérias produtoras de enzimas que degradam a lignina foram isoladas da palma, a saber: Bacillus sp., Ochrobactrum sp. e Leucobacter sp. As enzimas produzidas foram lignina peroxidase, manganês peroxidase e lacase em fermentação submersa. Depois as enzimas foram utilizadas na deslignificação dos cachos vazios da palma (empty fruit bunches - EFB) ${ }^{111}$.

No trabalho de Bandounas e colaboradores ${ }^{112}$, a mineralização e despolimerização da lignina são processos isolados e desafiam ainda mais a seleção de micro-organismos ligninolíticos produtores de enzimas ligninolíticas específicas.

O uso de fungos em projetos de degradação biológica é atraente devido ao seu baixo custo e ao seu sistema de hidrólise enzimática da lignocelulose. Como vantagens do pré-tratamento biológico podemos ressaltar: a baixa exigência de consumo de energia, pouca exigência química, condições ambientais suaves, produção de baixa quantidade de compostos inibidores da fermentação em relação a outros tipos de pré-tratamentos ${ }^{101}$, baixo custo e eficiente sistema de hidrólise ${ }^{106}$. Entretanto, o rendimento do tratamento é muito baixo na maioria dos processos biológicos ${ }^{105}$.

Devido ao baixo rendimento alguns tratamentos biológicos são realizados em conjunto com tratamentos físico-químicos. Um pré-tratamento combinado de Populus tomentosa utilizando fungos de degradação branca e o sistema LHW foi realizado por Wang et al. (2012). A combinação desses pré-tratamentos apresentou bom desempenho na remoção de hemicelulose e favoreceu a digestão da celulose quando comparada à utilização somente do tratamento LHW. A maior remoção de hemicelulose (92,33\%) foi observada pela combinação de Lenzites betulina com tratamento LHW, além de proporcionar um aumento de 2,66 vezes do rendimento de recuperação de glicose ${ }^{113}$. Para melhorar os resultados já citados de Tanigushi ${ }^{108}$, o autor testou os efeitos da explosão a vapor (1,5 $\mathrm{MPa}$, um minuto) combinado com o tratamento de palha de arroz com $P$. ostreatus e avaliou a alteração da composição dos componentes e a suscetibilidade à hidrólise enzimática. Quando a palha de arroz foi pré-tratada com explosão a vapor antes do tratamento biológico, o tempo de tratamento necessário para a obtenção de um xarope de glicose com $33 \%$ de rendimento foi reduzido de 60 para 36 dias. A redução se dá, provavelmente, devido ao afrouxamento das interações que formam a estrutura recalcitrante dos materiais lignocelulolíticos entre a lignina e os carboidratos durante o tratamento biológico ${ }^{114}$. 


\subsection{ENZIMAS QUE ATUAM NA DEGRADAC̣ÃO DOS MATERIAIS LIGNOCELULÓSICOS}

Enzimas lignocelulolíticas têm importantes aplicações em vários setores, incluindo a fabricação de produtos químicos, combustível, cerveja e vinho, alimentação animal, indústria têxtil e de lavanderia, papel e celulose e agricultura. Muitos estudos estão sendo realizados focados na redução do custo das enzimas, dentre os quais podemos destacar: screening de micro-organismos produtores de novas enzimas, melhoramento genético das cepas industriais existentes e engenharia enzimática, modelos de produção e operação de fatores relacionados, como escolha de substrato, condições de cultura, reciclagem de enzimas e remodelagem de processos $^{103}$.

A degradação da biomassa lignocelulósica necessita de um conjunto de enzimas que atuam sinergicamente para a hidrólise total, devido à complexidade do substrato. Três ou mais grupos diferentes de enzimas são normalmente necessários, dependendo do produto final desejado, ou o grau de hidrólise necessária. Os principais e seletivos grupos de enzimas incluem celulases, hemicelulases e ligninases.

Apesar de a celulose ser um homopolissacarídeo, fungos que degradam a celulose produzem enzimas que formam sistemas enzimáticos complexos. $\mathrm{O}$ Trichoderma reesei, fungo mais estudado para produção de celulases, produz duas celobiohidrolases, cinco endoglucanases e duas $\alpha$-glicosidases já caracterizadas; além dessas, três supostas endoglucanases e cinco $\beta$-glicosidases que foram identificadas com base na similaridade da sequência dos genes de enzimas conhecidas ${ }^{115}$.

Pelo menos três grupos de celulases estão envolvidos no processo de hidrólise da celulose: endoglucanase (EG; endo 1,4- $\beta$-D-glucanases ou endo-1,4-glucanohidrolase; EC 3.2.1.3) ataca as regiões de baixa cristalinidade da fibra de celulose, gerando extremidades livres; exoglucanase ou celobiohidrolase (CBH I e II ou ExG; $1,4-\beta$-glucano-celobiohidrolase ou exo-1,4- $\beta$-D-glucanase; EC 3.2.1.91), que degrada a molécula por remoção das unidades de celobiose e/ou glicose das extremidades livres, e o terceiro grupo de enzimas que trabalham em conjunto e em sinergia com a CBH e EG, são $\beta$-glucosidases (BG; EC 3.2.1.21), que hidrolisam a celobiose para produzir glicose $\mathrm{e}^{94,105,106,116}$. As celulases devem aderir à superfície das partículas do substrato antes da hidrólise da celulose. A estrutura 3D das partículas em combinação com sua forma e tamanho são determinantes para a suscetibilidade ou não das ligações $\beta$-glicosídicas à hidrólise enzimática ${ }^{116}$. 
EG tem um sítio ativo em formato de fenda aberta, o que permite a sua ligação em qualquer local ao longo da cadeia de polímero de celulose, mas mostra ser mais eficaz nas regiões amorfas, enquanto o sítio catalítico de ExG está dentro de um túnel formado na estrutura da enzima ${ }^{117,118}$.

Os micro-organismos mais utilizados na produção de enzimas celulolíticas incluem: espécies de fungos Trichoderma, Humicola, Penicillium e Aspergillus; bactérias Bacillus, Pseudomonas, Cellulomonas e actinomicetos Streptomyces e Actinomucor, sendo que o Trichodermea reesei é o principal produtor inclusive industrialmente, estando presente na preparação comercial Celluclast ${ }^{\circledR}$ da Novozymes.

No caso da hemicelulose, por apresentar composição tão heterogênea (pentoses, hexoses e/ou ácidos urônicos) ${ }^{119}$, mais enzimas são necessárias para atuar sinergicamente na sua hidrólise total em relação às enzimas que atuam na celulose ${ }^{120,121}$. A xilana é a hemicelulose mais abundante, e as enzimas xilanases são as hemicelulases mais indicadas para a hidrólise enzimática deste substrato ${ }^{103}$.

As endoxilanases atuam nas cadeias principais da xilana, e as $\beta$-xilosidades hidrolisam os xilo-oligossacarídeos em xilose. A $\alpha$-arabinofuranosidase e $\alpha$-glucuronidase removem a arabinose e os substituintes do ácido 4-O-metil glicurônico, respectivamente, das cadeias de xilana. Ainda, concorrem no processo as esterases hemicelulolíticas incluindo acetil esterases que hidrolisam os substituintes de acetil nas frações da xilose, e feruloil esterases que hidrolisam a ligação éster entre os substituintes de arabinose e ácido ferúlico. Feruloil esterases ajudam na liberação da fração hemicelulósica da lignina e tornam o polissacarídeo livre, mais favorável à degradação pelas outras hemicelulases ${ }^{116,103}$.

As xilanases auxiliam na catálise da hidrólise das ligações glicosídicas na cadeia da xilana, reduzindo o grau de polimerização do substrato, aumentando o brilho da polpa (facilitando, assim, a extração química da lignina da polpa celulósica na subsequente extração alcalina) e provocando a diminuição de interferentes na reação. Xilanases microbianas livres de celulase, alcalinas e termoestáveis são ideais para biopolpação e branqueamento de resíduos lignocelulósicos ${ }^{122}$.

Aspergillus niger, Humicola insolens, Termomonospora fusca, Trichoderma reesei, $T$. longibrachiatum e T. koningii têm sido utilizados como fontes industriais de xilanases comerciais. No entanto, as xilanases comerciais também podem ser obtidas por bactérias, por exemplo, a partir de Bacillus sp. Industrialmente, as xilanases têm importância nos segmentos de fabricação de papel, alimentação animal, panificação, indústrias de suco 
e vinho ou produção de xilitol ${ }^{119}$. As xilanases fúngicas possuem maior interesse em relação às bacterianas, uma vez que são secretadas no meio extracelular, facilitando, assim, sua recuperação do meio de cultivo ${ }^{122}$.

A dificuldade na degradação da lignina consiste na sua complexidade estrutural, seu elevado peso molecular e sua insolubilidade. Enzimas extracelulares, oxidativas e inespecíficas, que podem liberar produtos altamente instáveis e que ainda sofrem várias reações diferentes, catalisam a oxidação no início da despolimerização da lignina. Essa oxidação não específica da lignina tem sido denominada "combustão enzimática" 121 .

Há algumas enzimas que fazem a degradação eficaz do polímero de lignina, especificamente: manganês peroxidase $(\mathrm{MnP})$, lignina peroxidase (LiP), lacase, glicol-oxidase, oxidase de açúcar, álcool oxidase e quinona oxidorredutase $^{123}$. MnP e LiP oxidam o substrato por meio de dois passos consecutivos de oxidação de apenas um elétron por vez com a formação de radicais catiônicos intermediários, e possuem um elevado valor de potencial redox. Lacases são oxidases que catalisam a oxidação de um elétron de compostos fenólicos e outros substratos não fenólicos ricos em elétrons ${ }^{121}$. Níveis elevados de oxigênio aumentam a taxa de biodegradação da lignina através da produção de $\mathrm{H}_{2} \mathrm{O}_{2}$ como o oxidante extracelular e a indução subsequente de atividade ligninolítica ${ }^{106}$.

Enzimas ligninolíticas tem diversas aplicações biotecnológicas potenciais, dentre os quais podemos citar: indústria de alimentos (remoção de compostos fenólicos de alimentos e da cerveja, fonte natural de aromas); indústria de polpa e papel (despolimerização da lignina, deslignificação da polpa e branqueamento de polpa Kraft); indústria têxtil (degradação de corantes e branqueamento); biorremediação (biodegradação de xenobióticos); síntese orgânica; aplicações médicas, farmacológicas, em cosméticos e em nanotecnologia (produção de polímeros, biossensores, síntese de compostos funcionais, entre outros) $)^{124}$.

\subsection{PRODUTOS OBTIDOS DE MATERIAIS LIGNOCELULÓSICOS}

\subsubsection{Lignina}

Atualmente a valorização da lignina representa um desafio real, já que todo ano mais de 50 milhões de toneladas de lignina são coproduzidas na indústria de papel e queimadas para fornecer energia nesse campo de 
atividade. Porém, uma parte dessa lignina pode ser usada para outras aplicações sem prejuízo à indústria do papel ${ }^{125}$.

Dentre os usos da lignina temos os adesivos, resinas fenol-formaldeídos e resinas epóxi ${ }^{126}$. No caso do uso como adesivos, muito esforço tem sido feito para trocar o fenol por lignina ou tanino, com base na similaridade das estruturas ${ }^{127}$. Tradicionalmente utilizam-se adesivos termofixos em placas de fibra de madeira de média densidade (medium density fiberboard-MDF) e em particle boards, principalmente formados por ureia-formaldeído, melamina-ureia-formaldeído e fenol-formaldeído. Esses componentes são derivados do petróleo. Alternativamente, a lignina pode ser utilizada como capa na produção de $\mathrm{MDF}^{126}$.

Adesivos fenol-formaldeídos (ou resinas) são extensivamente usados na indústria da madeira pela alta performance incluindo altas forças de ligação, excelente resistência à água, resistência ao calor e estabilidade química ${ }^{128}$. $\mathrm{O}$ uso da resina lignina-fenol-formaldeído como adesivo em madeiras tem sido relatado em muitos artigos. Porém, há pouco sucesso no uso dessas resinas na indústria principalmente por razões técnicas e econômicas. Há duas maneiras principais de se preparar a resina: na primeira, a lignina é purificada e modificada para obter produtos puros e ativos. A segunda via é chamada de catch all, na qual se utiliza toda a lignina bruta sem purificação ${ }^{127}$. Resinas epóxi também são preparadas de materiais lignocelulósicos e são conhecidas por serem importantes polímeros termofixos, usados em adesivos, compósitos e elastômeros ${ }^{129}$.

\subsubsection{Hemicelulose}

As hemiceluloses são heteropolímeros de pentoses e hexoses além de conter desoxiaçúcares e ácidos urônicos, dependendo da espécie vegetal em questão, e correspondem a $10 \%$ a $40 \%$ da matéria seca dos resíduos lignocelulósicos. Essa fração pode ser convertida em açúcares monoméricos, principalmente xilose, em temperaturas abaixo de $200{ }^{\circ} \mathrm{C}$ na presença de ácidos diluídos ${ }^{130}$.

O principal componente da fração de hemicelulose de madeiras duras e dos resíduos agroindustriais é a xilana, polissacarídeo amorfo, formado por unidades de xilose e que pode ser hidrolisado a esse açúcar pela ação de ácidos em temperaturas brandas ${ }^{131}$. O resíduo sólido resultante da hidrólise ácida contém as frações de lignina e de celulose que podem ser separadas e utilizadas de maneiras diversas. A fase líquida resultante da hidrólise ácida 
contém o açúcar solúvel e pode ser utilizada como fonte de carbono em processos fermentativos como o da produção de xilitol ${ }^{132}$.

A xilose da hemicelulose também pode ser convertida em furfural, que é um dos insumos para a produção do nylon $6^{133}$, além de poder ser usado no refino de óleos de motores.

\subsubsection{Açúcares}

Bagaço de cana pré-processado termicamente em meio ácido produz como resíduo líquido licor de pentoses e hexoses da hidrólise da hemicelulose, que pode ser fermentado em etanol de segunda geração. A composição desse resíduo líquido varia com o tipo de processo de pré-tratamento utilizado, mas é composto basicamente por constituintes de lignina, mono e oligossacarídeos de hemicelulose e xilose, que é o principal carboidrato presente ${ }^{134}$.

A glicose se decompõe rapidamente quando em água supercrítica a 246 bar e de $425^{\circ} \mathrm{C}$ a $600{ }^{\circ} \mathrm{C}$, e gera uma diversa gama de produtos, dos quais os principais são ácido acético, acetonilacetona, ácido propenóico, acetaldeído, monóxido de carbono, dióxido de carbono, metano, etano, etileno e hidrogênio ${ }^{135}$.

\subsubsection{Etanol}

O aumento da preocupação com a emissão de $\mathrm{CO}_{2}$ e a limitada disponibilidade futura de recursos de petróleo têm aumentado o interesse na energia e combustível baseado em recursos renováveis ${ }^{136}$. A biomassa lignocelulósica é ainda considerada por muitos como a única fonte de carbono não fóssil, em larga escala, atualmente disponível. Muitas pesquisas têm sido realizadas quanto à viabilidade industrial e econômica da conversão da biomassa em energia, combustível, químicos e materiais.

Contrariamente aos combustíveis fósseis, o etanol é uma fonte de energia produzida através da fermentação de açúcares ${ }^{137}$. A bioconversão de materiais lignocelulósicos em biocombustíveis e outros produtos químicos está ganhando interesse pelo baixo custo, por ser matéria-prima renovável e pela alta disponibilidade na natureza ${ }^{138}$.

Hoje, os insumos utilizados para a produção de etanol são os açúcares de cana-de-açúcar e de beterraba, ou o amido encontrado nos grãos de cereais. 
Nos Estados Unidos e no Canadá, o milho é o insumo dominante usado pela indústria de etanol ${ }^{139}$.

A fermentação alcoólica eficiente de hidrolisado de lignocelulósicos requer que o micro-organismo utilizado fermente os açúcares, hexoses (glicose, manose e galactose) e pentoses (xilose e arabinose) na presença de compostos inibitórios, incluindo ácidos fracos, furaldeídos e fenólicos. A levedura Saccharomyces cerevisiae, que tem sido o organismo preferido para produção de etanol fermentativo, é tolerante aos inibidores presentes nos lignocelulósicos, mas não possui a habilidade de utilizar as pentoses, xilose e arabinose $\mathrm{e}^{140}$.

Singh et al. ${ }^{141}$ obtiveram uma produção de $0,42 \mathrm{~g}$ de etanol/g casca de arroz com uma cocultura de $S$. cerevisiae e Sheffersomyces stipitis e $50 \mathrm{~g} / \mathrm{L}$ de concentração de açúcares, principalmente glicose e xilose.

\subsection{CONCLUSÕES}

Materiais e resíduos lignocelulósicos agroindustriais são potencialmente a alternativa mais viável para a substituição parcial do petróleo e seus derivados. A lignocelulose é uma matéria-prima produzida por fotossíntese, ao contrário do petróleo, e está presente em todos os tipos de biomassa produzida, em qualquer centímetro quadrado de terra fértil onde houver disponibilidade de água e incidir luz solar.

Inseridos na matriz energética de povos e países desde épocas mais remotas, quando a simples queima da madeira era feita com o objetivo de gerar energia térmica, esse material têm hoje utilizações mais nobres, graças ao desenvolvimento científico em vários campos do conhecimento. Através de um processamento termoquímico adequado, os resíduos lignocelulósicos podem se transformar em uma fonte de açúcares, que são matérias-primas essenciais para inúmeros processos biotecnológicos. Por fermentação, com os nutrientes devidamente balanceados e um micro-organismo adequado, é possível produzir uma infinidade de produtos bioquímicos, incluindo enzimas, ácidos orgânicos, biocombustíveis, proteína unicelular, insumos e intermediários para a síntese de outros produtos poliméricos, com várias aplicações industriais. 


\subsection{PERSPECTIVAS FUTURAS}

Para viabilizar o uso adequado e racional dos materiais lignocelulósicos, muitas pesquisas ainda são necessárias para se definir o melhor processamento desse material estável e recalcitrante. As potencialidades de tal material justificam as inúmeras pesquisas e investimentos que estão sendo feitos em todo o mundo por entidades publicas e privadas.

A definição do melhor processo de pré-tratamento é imprescindível para recuperar com o máximo rendimento possível as três frações majoritárias constituintes do material lignocelulósico, considerando ainda a menor degradação dessas e a baixa geração de compostos tóxicos, bem como danos ambientais de qualquer natureza. 


\section{REFERÊNCIAS}

1. Cherubini F. The biorefinery concept: Using biomass instead of oil for producing energy and chemicals. Energy Conversion and Management. 2010;51(7), 1412-21.

2. Hamelinck CN, Hooijdonk GV, Faaij AP. Ethanol from lignocellulosic biomass: techno-economic performance in short- middle- and long-term. Biomass and Bioenergy 2005;28(4):384-410.

3. Rabelo SC, Carrere H, Maciel Filho R, Costa C. Production of bioethanol, methane and heat from sugarcane bagasse in a biorefinery concept. Bioresource Technology. 2011;102(17):7887-95.

4. Dias MOS, Junqueira TL, Cavalett O, Pavanello LG, Cunha MP, Jesus CDF, Bonomi A. Biorefineries for the production of first and second generation ethanol and electricity from sugarcane. Applied Energy. 2013;109:72-8.

5. Pessoa Jr. A, Klikikian BV. Purificação de Produtos Biotecnológicos. São Paulo: Ed. Manole; 2005.

6. Alvira P, Tomás-Pejó E, Ballesteros M, Negro MJ. Pretreatment technologies for an efficient bioethanol production process based on enzymatic hydrolysis: A review. Bioresource Technology. 2010;101(13):4851-61.

7. Mosier N, Wyman C, Dale B, Elander R, Lee YY, Holtzapple M, Ladisch M. Features of promising technologies for pretreatment of lignocellulosic biomass. Bioresource Technology. 2005;96:673-86.

8. Wyman CE, Dale BE, Elander RT, Holtzapple M, Ladisch MR, Lee YY. Coordinated development of leading biomass pretreatment technologies. Bioresource Technology 2005;96:1959-66.

9. Haghighi M, Sohrab et al. Lignocellulosic biomass to bioethanol, a comprehensive review with a focus on pretreatment. Renewable and Sustainable Energy Reviews. 2013;27:77-93.

10. Grzegorz B, Cybulska I, Rosentrater K. Integration of extrusion and clean fractionation processes as a pre-treatment technology for prairie cordgrass. Bioresource Technology. 2013;135:672-82.

11. Chandra RP, et al. Substrate pretreatment: the key to effective enzymatic hydrolysis of lignocellulosics? Advances in biochemical engineering/biotechnology. 2007;108(5):67-93.

12. Boullanger E. Distillerie agricole et industrielle [Internet]. Paris: J. P. Baillière et Fils; 1924. [Cited 2013 Nov 26] Available from: http://www.green-trust.org/2000/biofuel/ wood_alc.pdf.

13. Silva FV. Panorama e perspectivas do etanol lignocelulósico. Revista Liberato. 2012;13(20):1-134. 
14. Dyk JS, Pletschke BI. A review of lignocellulose bioconversion using enzymatic hydrolysis and synergistic cooperation between enzymes - Factors affecting enzymes, conversion and synergy. Biotechnology Advances. 2012;30:1458-80.

15. Sukhbaatar B, Hassan EB, Kim M, Steele P, Ingram L. Optimization of hot-compressed water pretreatment of bagasse and characterization of extracted hemicelluloses. Carbohydrate Polymers. 2014;101:196-202.

16. Yuan TQ, You TT, Wang W, Xua F, Sun RC. Synergistic benefits of ionic liquid and alkaline pretreatments of poplar wood. Part 2: Characterization of lignin and hemicelluloses. Bioresource Technology. 2013;136:345-50.

17. Jiang H, Chen Q, Ge J, Zhang Y. Efficient extraction and characterization of polymeric hemicelluloses from hybrid poplar. Carbohydrate Polymers. 2014;101:1005-12.

18. Peng F, Peng P, Xu F, Sun RC. Fractional purification and bioconversion of hemicelluloses. Biotechnology Advances. 2012;30:879-903.

19. Kang S, Li X, Fan J, Chang J. Hydrothermal conversion of lignin: A review. Renewable and Sustainable Energy Reviews. 2013;27:546-58.

20. Cardona CA, Quintero, JA, Paz IC. Production of bioethanol from the sugar cane bagasse: Status and Perspectives. Bioresource Technology. 2010;101:4754-60.

21. Jeffries TW. Biodegradation of lignin-carbohydrate complexes. Biodegradation. 1990;1:163-76.

22. Delmer DP, Amor Y. Cellulose biosynthesis. The Plant cell. 1995;7:987-1000.

23. Lora JS, Glasser WG. Recent Industrial applications of lignin: A sustainable alternative to Nonrenewable materials. Journal of Polymers Environment. 2002;10:39-48.

24. Kadla JK, Kubo S, Venditti RA, Gilbert RD, Compere AL, Griffith W. Lignin-based carbon fibers for composite fiber applications. Carbon. 2002;40:2913-20.

25. Kadam KL, Forrest LH, Jacobson WA. Rice straw as a lignocellulosic resource: collection, processing, transportation, and environmental aspects. Biomass and Bioenergy. 2000;18:369-89.

26. Cerqueira DA, Rodrigues-Filho G, Meireles CS. Optimization of sugarcane bagasse acetylation. Carbohydrate Polymers. 2007;69:579-82.

27. Rodrigues-Filho G, Ribeiro SD, Meireles CS, Silva LG, Ruggiero R, Junior MFF, Cerqueira DA, Assunção RMN, Zeni M, Polleto P. Release of doxycycline through cellulose acetate symmetric and asymmetric membranes produced from recycled agroindustrial residue: Sugarcane bagasse. Industrial Crops and Products. 2011;7:566-71. 28. Luz SM, Del Tio J, Rocha GJM, Gonçalves AR, Del'arco Jr AP. Cellulose and cellulignin from sugarcane bagasse reinforced polypropylene composites: Effect of acetylation on mechanical and thermal properties. Composites Part A: Applied Science and Manufacturing. 2008;39:1362-9. 
29. Cerqueira DA, Valente AJM, Rodrigues Filho G, Burrows HD. Synthesis and properties of polyaniline-cellulose acetate blends: The use of sugarcane bagasse waste and the effect of the substitution degree. Carbohydrate Polymers. 2009;78:402-8.

30. Corradini E, Ito EN, Marconcini JM, Rios CT, Agnelli JAM, Mattoso LHC. Interfacial behavior of composites of recycled poly(ethyelene terephthalate) and sugarcane bagasse fiber. Polymer Testing. 2009;28:183-7.

31. Mulinari DR, Voorwald JCH, Cioffi MOH, Silva MLCP, Cruz TG, Saron C. Sugarcane bagasse cellulose/HDPE composites obtained by extrusion. Composites Science and Technology. 2009;69:214-9.

32. Carrasco C, Baudel HM, Sendelius J, Modig T, Roslander C, Galbe M, HahnHägerdal B, Zacchi G, Lidén G. SO2-catalyzed steam pretreatment and fermentation of enzymatically hydrolyzed sugarcane bagasse. Enzyme and Microbial Technology. 2010;46:64-73.

33. Dias MOS, Modesto M, Ensinas AV, Nebra SA, Filho RM, Rossell CEV. Improving bioethanol production from sugarcane: evaluation of distillation, thermal integration and cogeneration systems. Energy. 2011;36:3691-703.

34. Soares IB, Travassos JA, Baudel HM, Benachour M, Abreu CAM. Effects of washing, milling and loading enzymes on the enzymatic hydrolysis of a steam pretreated sugarcane bagasse. Industrial Crops and Products. 2011;33:670-5.

35. Cunha MAA, Silva SS, Carvalho W, Santos JC. Uso de células imobilizadas em gel de PVA: uma nova estratégia para produção biotecnológica de xilitol a partir de bagaço de cana-de-açúcar. Semina: Ciências Agrárias. 2005;26:61-70.

36. Jorapur R, Rajvanshi AK. Development of a sugarcane leaf gasifier for electricity generation. Biomass and Bioenergy. 1995;8:91-8.

37. Silva AS, Inoue H, Endo T, Yano S, Bon ESP. Milling pretreatment of sugarcane bagasse and straw for enzymatic hydrolysis and ethanol fermentation. Bioresource Technology. 2010;101:7402-9.

38. Park J, Shiroma R, Al-Haq MI, Zhang Y, Ike M, Arai-Sanoh Y, Ida A, Kondo M, Tokuyasu K. A novel lime pretreatment for subsequent bioethanol production from rice straw - Calcium capturing by carbonation ( $\mathrm{CaCCO}$ ) process. Bioresource Technology. 2010;101:6805-11.

39. Gonçalves AR, Moriya RY, Oliveira LRM, Saad MBW. Xylanase recycling for the economical biobleaching of sugarcane bagasse and straw pulps. Enzyme and Microbial Technology. 2008;43:157-63.

40. Saad MBW, Oliveira LRM, Cândido RG, Quintana G, Rocha GJM, Gonçalves AR. Preliminary studies on fungal treatment of sugarcane straw for organosolv pulping. Enzyme and Microbial Technology. 2008;43:220-5.

41. Huang G, Shi JX, Langrish TAG. NH4OH-KOH pulping mechanisms and kinetics of rice straw. Bioresource Technology. 2007;98:1218-23. 
42. Rodríguez A, Sánchez R, Requejo A, Ferrer A. Feasibility of rice straw as a raw material for the production of soda cellulose pulp. Journal of Cleaner Production. 2010;18:1084-91.

43. Hedjazi S, Kordsachia O, Patt R, Latibari AJ, Tschirner U. Alkaline sulfiteanthraquinone (AS/AQ) pulping of wheat straw and totally chlorine free (TCF) bleaching of pulps. Industrial Crops and Products. 2009;29:27-36.

44. Li Z, Liu Y, Liao W, Chen S, Zemetra RS. Bioethanol production using genetically modified and mutant wheat and barley straws. Biomass and Bioenergy. 2011;35:542-8.

45. Wan C, Li Y. Microbial pretreatment of corn stover with Ceriporiopsis subvermispora for enzymatic hydrolysis and ethanol production. Bioresource Technology. 2010;101:6398-403.

46. Zhong W, Zhang Z, Qiao W, Fu P, Liu M. Comparison of chemical and biological pretreatment of corn straw for biogas production by anaerobic digestion. Renewable Energy. 2011;36:1875-9.

47. Goelzer FDE, Faria-Tischer PCS, Vitorino JC, Sierakowski MR, Tischer CA. Production and characterization of nanospheres of bacterial cellulose from Acetobacter xylinum from processed Rice bark. Materials Science and Engeneering C. 2009;29:546-51.

48. Stradiotto NR, Lemos EGM. Resíduos agrícolas e agroindustriais: potencialidades de uso na produção de etanol. In: Bioenergia. São Paulo: Cultura Acadêmica, 2012. Capítulo 10.

49. Sanderson K. Lignocellulose: A chewy problem. Nature. 2011;474:12-4.

50. MAPA [Internet]. [Cited 2016 Nov 3]. Dados Básicos de Economia Agrícola. 2013 Oct. Available from: http://www.agricultura.gov.br/arq_editor/Pasta\%20de\%20 Outubro\%20(1).pdf.

51. CONAB [Internet]. [Cited 2016 Nov 3]. Acompanhamento da safra brasileira. 2013. Available from: http://www.conab.gov.br/conteudos. php?a=1253\&t=2\&Pagina_objcmsconteudos=3\#A_objcmsconteudos.

52. Huang CF, Ting-Hsiang L, Gia-Luen G, Wen-Song H. Enhanced ethanol production by fermentation of rice straw hydrolysate without detoxification using a newly adapted strain of Pichia stipitis. Bioresource Technology. 2009;100(17):3914-20.

53. Panagiotopoulos IA, Bakker RR, De Vrije T, Koukios EG. Effect of pretreatment severity on the conversion of barley straw to fermentable substrates and the release of inhibitory compounds. Bioresource Technology. 2011;102(24):11204-11.

54. Kim JS, Won IC, Minsu K, Ji YP, Jin-Suk L. Kinetic study of empty fruit bunch using hot liquid water and dilute acid. Applied Biochemistry and Biotechnology. 2012;167(6):1527-39.

55. Saha BC, Iten LB, Cotta MC, Wu YV. Dilute acid pretreatment, enzymatic saccharification and fermentation of wheat straw to ethanol. Process Biochemistry. 2005;40(12):3693-700. 
56. Rahman SH, Choudhury JP, Ahmad L, Kamaruddin H. Optimization studies on acid hydrolysis of oil palm empty fruit bunch fiber for production of xylose. Bioresource Technology. 2007;98(3):554-9.

57. Chen WH, Yi-Jian T, Herng-Kuang S. Disruption of sugarcane bagasse lignocellulosic structure by means of dilute sulfuric acid pretreatment with microwave-assisted heating. Applied Energy. 2011;88(8):2726-34.

58. Zhang D, Ong YL, Li Z, Wu JC. Optimization of dilute acid-catalyzed hydrolysis of oil palm empty fruit bunch for high yield production of xylose. Chemical Engineering Journal. 2012;181-182:636-42.

59. Meena K, Kumar V, Vijay VK, Malik A. Analysis of different techniques used for improvement of biomethanation process: A review. Fuel. 2013;106:1-9.

60. Ziyu W, Keshwani DR, Redding AP, Cheng JJ. Sodium hydroxide pretreatment and enzymatic hydrolysis of coastal Bermuda grass. Bioresource Technology. 2010;101(10):3583-5.

61. Haghighi MHS, Hossein Golfeshan A, Tabatabaei M, Salehi Jouzani G, Najafi GH, Gholami M, Ardjmand M. Lignocellulosic biomass to bioethanol, a comprehensive review with a focus on pretreatment. Renewable and Sustainable Energy Reviews. 2013;27:77-93.

62. Moradi F, Amiri H, Soleimanian-Zad S, Ehsani MR, Karimi K. Improvement of acetone, butanol and ethanol production from rice straw by acid and alkaline pretreatments. Fuel. 2013;112:8-13

63. Rocha GJM, Gonçalves R, Oliveira BR, Olivares EG, Rossell CEV. Steam explosion pretreatment reproduction and alkaline delignification reactions performed on a pilot scale with sugarcane bagasse for bioethanol production. Industrial Crops and Products. 2012;35(1):274-9.

64. Subhedar PB, Gogate PP. Alkaline and ultrasound assisted alkaline pretreatment for intensification of delignification process from sustainable raw-material. Ultrasonics Sonochemistry. 2014;21(1):216-25.

65. Wei WB, Li L, Chang L, Wang Z. Chemical and structural characterization of alkaline-extractable hemicelluloses from various eucalyptus species. Journal of Applied Polymer Science. 2013;130(4):2390-8.

66. William EK, Holtzapple MT. Using lime pretreatment to facilitate the enzymic hydrolysis of corn stover. Biomass and Bioenergy. 2000;18:189-99.

67. Ko JK, et al. Ethanol production from rice straw using optimized aqueous-ammonia soaking pretreatment and simultaneous saccharification and fermentation processes. Bioresource Technology. 2009;100(19):4374-80.

68. Xuan L, Kim TH. Low-liquid pretreatment of corn stover with aqueous ammonia. Bioresource technology. 2011;102(7):4779-86. 
69. Jung YH, Kim IJ, Han J-I, Choi I-G, Kim KH. Aqueous ammonia pretreatment of oil palm empty fruit bunches for ethanol production. Bioresource Technology. 2011;102(20):9806-9.

70. Peng F, Peng P, Xu F, Sun R-C. Fractional purification and bioconversion of hemicelluloses. Biotechnology Advances. 2012;30(4):879-903.

71. Brienzo M, Siqueira F, Milagres MF. Search for optimum conditions of sugarcane bagasse hemicellulose extraction. Biochemical Engineering Journal. 2009;46(2):199-204. 72. Hosseini SA, Shah N. Multiscale modelling of hydrothermal biomass pretreatment for chip size optimization. Bioresource technology. 2009;100(9):2621-8.

73. Martín-Sampedro R, Eugenio ME, García JC, Lopez F, Villar JC, Diaz MJ. Steam explosion and enzymatic pre-treatments as an approach to improve the enzymatic hydrolysis of Eucalyptus globulus. Biomass and Bioenergy. 2012;42:97-106.

74. Martin-Sampedro R, Eugenio ME, Revilla E, Martín JA, Villar JC. Biorefinery by the addition of a steam explosion. bioresources.com. 2011;6:513-28.

75. Baharuddin AS, Sulaiman A, Kim DH, Mokhtar MN, Hassan MA, Wakisaka M, Nishida H. Selective component degradation of oil palm empty fruit bunches (OPEFB) using high-pressure steam. Biomass and Bioenergy. 2013;1-8.

76. Cara C, Ruiz E, Ballesteros I, Negro MJ, Castro E. Enhanced enzymatic hydrolysis of olive tree wood by steam explosion and alkaline peroxide delignification. Process Biochemistry. 2006;41(2):423-9.

77. Chang J, Cheng W, Yin Q, Zuo R, Song A, Zheng Q, Liu J. Effect of steam explosion and microbial fermentation on cellulose and lignin degradation of corn stover. Bioresource Technology. 2012;104:587-92.

78. Datar R, Huang J, Maness P, Mohagheghi A, Czernik S, Chornet E. Hydrogen production from the fermentation of corn stover biomass pretreated with a steamexplosion process. International Journal of Hydrogen Energy. 2007;32(8):932-9.

79. Ruiz E, Cara C, Manzanares P, Ballesteros M, Castro E. Evaluation of steam explosion pre-treatment for enzymatic hydrolysis of sunflower stalks. Enzyme and Mcrobial Technology. 2008;42(2):160-6.

80. Chen WH, Pen BL, Yu CT, Hwang WS. Pretreatment efficiency and structural characterization of rice straw by an integrated process of dilute-acid and steam explosion for bioethanol production. Bioresource Technology. 2011;102(3):2916-24.

81. Chiaramonti D, Prussi M, Ferrero S, Oriani L, Ottonello P, Torre P, Cherchi F. Review of pretreatment processes for lignocellulosic ethanol production, and development of an innovative method. Biomass and Bioenergy. 2012;46:25-35.

82. Kovacs K, Macrelli S, Szakacs G, Zacchi G. Enzymatic hydrolysis of steam-pretreated lignocellulosic materials with Trichoderma atroviride enzymes produced in-house. Biotechnology for Biofuels. 2009;2:14. 
83. Liu ZH, Qin L, Pang F, Jin MJ, Li BZ, Kang Y,Yuan YJ. Effects of biomass particle size on steam explosion pretreatment performance for improving the enzyme digestibility of corn stover. Industrial Crops and Products. 2013;44:176-84.

84. Shamsudin S, Md Shah UK, Zainudin H, Abd-Aziz S, Mustapa Kamal SM, Shirai Y, Hassan MA. Effect of steam pretreatment on oil palm empty fruit bunch for the production of sugars. Biomass and Bioenergy. 2012;36:280-8.

85. Agbor VB, Cicek N, Sparling R, Berlin A, Levin DB. Biomass pretreatment: fundamentals toward application. Biotechnology Advances. 2011;29(6):675-85.

86. Laser M, Schulman D, Allen SG, Lichwa J, Antal MJ, Lynd LR. A comparison of liquid hot water and steam pretreatments of sugar cane bagasse for bioconversion to ethanol. Bioresource Technology. 2002;81(1):33-44.

87. Sarkar N, Ghosh SK, Bannerjee S, Aikat K. Bioethanol production from agricultural wastes: An overview. Renewable Energy. 2012;37(1):19-27.

88. Wan C, Li Y. Bioresource Technology Effect of hot water extraction and liquid hot water pretreatment on the fungal degradation of biomass feedstocks. Bioresource Technology. 2011;102(20):9788-93.

89. Allen SG, Schulman D, Lichwa J, Antal MJ, Laser M, Lynd LR. A Comparison between Hot Liquid Water and Steam Fractionation of Corn Fiber. Industrial \& Engineering Chemistry Research. 2001;40(13):2934-41.

90. Hongdan Z, Shaohua X, Shubin W. Enhancement of enzymatic saccharification of sugarcane bagasse by liquid hot water pretreatment. Bioresource Technology. 2013;143: 391-6.

91. Pérez JA, Ballesteros I, Ballesteros M, Sáez F, Negro MJ, Manzanares P. Optimizing Liquid Hot Water pretreatment conditions to enhance sugar recovery from wheat straw for fuel-ethanol production. Fuel. 2008;87:3640-7.

92. Yu Q, Zhuang X, Yuan Z, Wang Q, Qi W, Wang W, Xu H. Two-step liquid hot water pretreatment of Eucalyptus grandis to enhance sugar recovery and enzymatic digestibility of cellulose. Bioresource Technology. 2010;101(13):4895-9.

93. Balat M. Production of bioethanol from lignocellulosic materials via the biochemical pathway: A review. Energy Conversion and Management. 2011;52(2):858-75.

94. Sarkar N, Ghosh SK, Bannerjee S, Aikat K. Bioethanol production from agricultural wastes: An overview. Renewable Energy. 2012;37(1):19-27.

95. Bals B, Wedding C, Balan V, Sendich E, Dale B. Bioresource Technology Evaluating the impact of ammonia fiber expansion (AFEX) pretreatment conditions on the cost of ethanol production. Bioresource Technology. 2011;102(2):1277-83.

96. Lee JM, Jameel H, Venditti RA. Bioresource Technology A comparison of the autohydrolysis and ammonia fiber explosion (AFEX) pretreatments on the subsequent enzymatic hydrolysis of coastal Bermuda grass. Bioresource Technology. 2010;101(14):5449-58. 
97. Wu-haan W. Evaluation of ultrasonic pretreatment on anaerobic digestion of biomass for methane production. Ames: Iowa State University; 2008.

98. Ninomiya K, Kamide K, Takahashi K, Shimizu N. Enhanced enzymatic saccharification of kenaf powder after ultrasonic pretreatment in ionic liquids at room temperature. Bioresource Technology. 2012;103(1):259-65.

99. Yunus R, Salleh SF, Abdullah N, Biak DRA. Effect of ultrasonic pre-treatment on low temperature acid hydrolysis of oil palm empty fruit bunch. Bioresource Technology. 2010;101(24):9792-6.

100. Velmurugan R, Muthukumar K. Ultrasound-assisted alkaline pretreatment of sugarcane bagasse for fermentable sugar production: optimization through response surface methodology. Bioresource Technology. 2012;112:293-9.

101. Sánchez OJ, Cardona CA. Trends in biotechnological production of fuel ethanol from different feedstocks. Bioresource Technology. 2008;99:5270-95.

102. Mtui GYS. Recent advances in pretreatment of lignocellulosic wastes and production of value added products. African Journal of Biotechnology. 2009;8(8):1398-1415.

103. Howard RL, Abotsi EL, Howard S. Lignocellulose biotechnology : issues of bioconversion and enzyme production. African Journal of Biotechnology 2003;2(12): 602-19.

104. Leonowicz A, Matuszewska A, Luterek J, et al. Biodegradation of lignin by white rot fungi. Fungal Genetics and Biology. 1999;27(2-3)175-85.

105. Sun Y, Cheng J. Hydrolysis of lignocellulosic materials for ethanol production : a review. Bioresource Technology. 2002;83:1-11.

106. Sánchez C. Lignocellulosic residues: biodegradation and bioconversion by fungi. Biotechnology Advances. 2009;27(2):185-94.

107. Moyson E, Verachtert H. Growth of higher fungi on wheat straw and their impact on the disgestibility of the substrate. Applied Microbiology and Biotechnology. 1991:421-4.

108. Taniguchi M, Suzuki H, Watanabe D, et al. Evaluation of pretreatment with Pleurotus ostreatus for enzymatic hydrolysis of rice straw. Journal of Bioscience and Bioengineering. 2005;100(6):637-43.

109. Dias AA, Freitas GS, Marques GSM, et al. Enzymatic saccharification of biologically pre-treated wheat straw with white-rot fungi. Bioresource Technology. 2010;101(15):6045-50.

110. Arora A, Nain L, Gupta JK. Solid-state fermentation of wood residues by Streptomyces griseus B1, a soil isolate, and solubilization of lignins. World Journal of Microbiology and Biotechnology. 2005;21(3)303-8.

111. Hashimah N, Rahman A, Aini N, Aziz SA, Hassan MA. Production of Ligninolytic Enzymes by Newly Isolated Bacteria from Palm Oil Plantation Soils. 2013;8:6136-50. 
112. Bandounas L, Wierckx NJ, De Winde JH, Ruijssenaars HJ. Isolation and characterization of novel bacterial strains exhibiting ligninolytic potential. BMC Biotechnology. 2011;11(1):94.

113. Wang W, Yuan T, Wang K, Cui B, Dai Y. Combination of biological pretreatment with liquid hot water pretreatment to enhance enzymatic hydrolysis of Populus tomentosa. Bioresource Technology. 2012;107:282-6.

114. Taniguchi M, Takahashi D, Watanabe D, et al. Effect of steam explosion pretreatment on treatment with Pleurotus ostreatus for the enzymatic hydrolysis of rice straw. Journal of bioscience and bioengineering. 2010;110(4):449-52.

115. Jørgensen H, Kristensen JB, Felby C. Enzymatic conversion of lignocellulose into fermentable sugars: challenges and opportunities. 2007:119-34.

116. Balat M. Production of bioethanol from lignocellulosic materials via the biochemical pathway. A review. Energy Conversion and Management. 2011;52(2): 858-75.

117. Zhang YHP, Lynd LR. Toward an aggregated understanding of enzymatic hydrolysis of cellulose: noncomplexed cellulase systems. Biotechnology and Bioengineering. 2004;88(7):797-824.

118. Hildén L, Johansson G. Recent developments on cellulases and carbohydratebinding modules with cellulose affinity. Biotechnology Letters. 2004;26(22):1683-93. 119. Gírio FM, Fonseca C, Carvalheiro F, et al. Hemicelluloses for fuel ethanol: A review. Bioresource Technology. 2010;101(13):4775-800.

120. Malherbe S, Cloete TE. Lignocellulose biodegradation : Fundamentals and applications. Re/Views in Environmental Science \& Bio/Technology. 2002;(1):105-14. 121. De Alencar Guimaraes NC, Sorgatto M, Peixoto-Nogueira SDC, et al. Bioprocess and biotecnology: effect of xylanase from Aspergillus niger and Aspergillus flavus on pulp biobleaching and enzyme production using agroindustrial residues as substract. SpringerPlus. 2013;2(1):380.

122. Pérez J, Muñoz-Dorado J, De La Rubia T, Martínez J. Biodegradation and biological treatments of cellulose, hemicellulose and lignin: an overview. International Microbiology: The Official Journal of the Spanish Society for Microbiology. 2002;5(2): 53-63.

123. Sarikaya A, Ladisch MR. Mechanism and potential applications of bio-ligninolytic systems in a CELSS. Applied Biochemistry and Biotechnology. 1997;62(2-3):131-49.

124. Maciel MMJ, Castro E Silva A, Telles Ribeiro HC. Industrial and biotechnological applications of ligninolytic enzymes of the basidiomycota: a review. Electronic Journal of Biotechnology. 2010;13(6):1-13.

125. Joffres B, et al. Catalytic Hydroconversion of a wheat straw soda lignin: Characterization of the products and the lignin residue. Applied Catalysis B: Environmental. 2014;145:167-76.

126. Seyed HG, Mizi F. Lignin in straw and its applications as an adhesive. International Journal of Adhesion \& Adhesives. 2014;48:92-101. 
127. Zhang W, Ma Y, Xu Y, Wang C, Chu F. Lignocellulosic ethanol residue-based ligninphenol-formaldhyde resin adhesive. International Journal of Adhesives \& Adhesives. 2013;40:11-18.

128. Jin Y, Cheng C, Zheng Z. Preparation and characterization of phenol-formaldehyde adhesives modified with enzymatic hydrolysis lignin. Bioresource Technology. 2010;101:2046-8.

129. Hirose S, Hatakeyama T, Hatakeyama H. Novel Epoxy Resins Derived from Biomass Components. Procedia Chemistry. 2012;4:26-33.

130. Neureiter $\mathrm{M}$, et al. Dilute-acid hydrolysis of sugarcane bagasse at varying conditions. Applied Biochemistry and Biotechnology. 2002;98:49-58.

131. Bier MCJ, et al. Crescimento e consumo de Xilose de Candida guilliermondii na fermentação submersa utilizando-se bagaço de cana-de-açúcar. Evidência. 2007;7:119-30. 132. Parajó JC, Dominguez HD, Domingues JM. Biotechnological Production of Xylitol. Part 3: Operation in Culture Media Made From Lignocellulose Hydrolisates. Bioresource Technology. 1998;66:25-40.

133. Fernando S, Adhikari S, Chandrapal C, Murali N. Biorefineries: Current Status, Challenges and Future Direction. Energy \& Fuels. 2007;20:1727-37.

134. Canilha L, et al. Bioconversion of Sugarcane Biomass into Ethanol: An Overview about Composition, Pretreatment Methods, Detoxification of Hydrolysates, Enzymatic Saccharification, and Ethanol Fermentation. Journal of Biomedicine and Biotechnology. 2012; Article ID 989572, 15 pages. http://dx.doi.org/10.1155/2012/989572

135. Holgate HR, et al. Glucose hydrolysis and oxidation in supercritical water. AIChE J. 2004;41(3):637-48.

136. Moe ST, Janga KK, Hertzberg T, Hägg MB, Øyaas K, Dyrset N. Saccharification of lignocellulosic biomass for biofuel and biorefinery applications - A renaissance for the concentrated acid hydrolysis? Energy Procedia. 2012;20:50-8.

137. Sun T, Cheng J. Hydrolysis of lignocellulosic materials for ethanol production: a review. Bioresource Technology. 2002;83:1-11.

138. Sudiyani Y, et al. Utilization of biomass waste empty fruit bunch fiber of palm oil for bioethanol production using pilot - scale unit. Energy Procedia. 2013;32:31-8. 139. Mabee WE, McFarlane PN, Saddler JN. Biomass availability for lignocellulosic ethanol production. Biomass and Bioenergy. 2011;35:4519-29.

140. Viikari L, Vehmannperä J, Koivula A. Lignocellulosic ethanol: From science to industry. Biomass and Energy. 2012;46:13-24.

141. Singh A, Bajar S, Bishnoi NR. Enzymatic hydrolysis of microwave alkali pretreated rice husk for ethanol production by Saccharomyces cerevisiae, Scheffersomyces stipitis and their co-culture. Fuel. 2014;116:699-702. 